\title{
INICIATIVAS ECONÔMICAS SOLIDÁRIAS E REDES DE COLABORAÇÃO NA AMAZÔNIA MARAJOARA
} Solidary Economic Initiatives and Collaboration Networks In Amazônia Marajoara

\author{
Alexandre Nunes da Silva \\ Mestrando em Gestão de Recursos Naturais e Desenvolvimento \\ Local na Amazônia pela Universidade Federal do Pará. Docente do \\ Instituto Federal do Instituto Federal de Educação, Ciência \\ Tecnologia do Pará. Breves, Brasil. \\ alexandre.nunes@ifpa.edu.br \\ Gilberto Miranda Rocha \\ Doutor em Geografia pela Universidade de São Paulo. Docente da \\ Universidade Federal do Pará, Núcleo de Meio Ambiente. Belém, \\ Brasil. \\ gilrocha@ufpa.br \\ Maria do Socorro Almeida Flores \\ Doutora em Direito pela Universidade Federal do Pará. Docente da \\ Universidade Federal do Pará, Núcleo de Meio Ambiente. Belém, \\ Brasil. \\ saflores@ufpa.br
}

A lista completa com informações dos autores está no final do artigo

\begin{abstract}
RESUMO
A pesquisa visa apresentar um estudo de caso que contextualiza o tema Economia Solidária à luz do que vem sendo construído no âmbito do território da Amazônia Marajoara, tendo como universo da pesquisa o Projeto Estadual de Assentamento Agroextrativista (PEAEX) denominado Acutipereira, mais especificamente, a comunidade Santo Ezequiel Moreno e suas redes de colaboração solidária com as demais comunidades adjacentes. $O$ objetivo da pesquisa concentrou-se em apresentar iniciativas econômicas solidárias em andamento na Amazônia Marajoara que se mostram promissoras na busca da melhor gestão dos recursos naturais e desenvolvimento local sustentável, avaliar as dinâmicas das redes de colaboração solidárias existentes e potenciais, bem como suas reais possibilidades e limites para o sucesso. Os procedimentos metodológicos utilizados foram a pesquisa bibliográfica, pesquisa documental e pesquisa de campo, com o uso do método qualitativo, com abordagem do tipo exploratória, por meio de um estudo de caso. Destaca-se como resultado que a comunidade se encontra em plena construção de uma cultura solidária, mas que ainda requer dar um salto de qualidade, tanto no amadurecimento e operacionalização de seus projetos, no efetivo acesso à novos mercados, quanto no aprimoramento e operacionalização de suas redes de colaboração solidárias dentro e fora do PEAEX Acutipereira. Conclui-se que as iniciativas econômicas solidárias e suas redes de colaboração em operacionalização na comunidade pesquisa de fato estão proporcionando geração de trabalho, renda e melhores condições de vida as famílias.
\end{abstract}

PALAVRAS-CHAVE: Desenvolvimento Local. Emancipação Social. Sustentabilidade. Cooperação. Autogestão.

\begin{abstract}
The research aims to present a case study that contextualizes the theme Solidarity Economy in the light of what is being built within the territory of the Marajoara Amazon. The analyzed case is the State Project for Agroextractive Settlement (PEAEX) called Acutipereira, more specifically the community Santo Ezequiel Moreno and its networks of solidarity collaboration with the other adjacent communities. The objective of the research was to present solidarity-based economic initiatives ongoing in the Amazon region of Marajó which are promising in the search for better management of natural resources and sustainable local development; as well as assessing the dynamics of existing and potential solidarity collaboration networks and its real possibilities and limits for success. The methodological procedures used were bibliographic research, documentary research and field research, using qualitative methods with an exploratory approach applied to the case study. The results show the community is in fully engaged in the construction of a solidary culture, but it still requires leaping in quality, both in the maturation and operationalization of its projects, but also in the effective access to new markets, and improvement and operationalization of its solidarity collaboration networks inside
\end{abstract}


and outside PEAEX Acutipereira. It is concluded that the solidary economic initiatives and their collaboration networks in operation in the researched community are providing families with jobs, income and better living conditions.

KEYWORDS: Local Development. Social Emancipation. Sustainability. Cooperation. Self-management.

\section{INTRODUÇÃO}

A pesquisa visa apresentar um estudo de caso que contextualiza o tema Economia Solidária a luz do que vem sendo construído no âmbito do território da Amazônia marajoara, tendo como universo da pesquisa o Projeto Estadual de Assentamento Agroextrativista (PEAEX), denominado Acutipereira, mais especificamente, a comunidade Santo Ezequiel Moreno e suas redes de colaboração solidária com as demais comunidades adjacentes.

A comunidade rural Santo Ezequiel Moreno fica localizada em um assentamento rural no município de Portel, estado do Pará, e caracteriza-se como uma experiência relevante que tem a solidariedade como foco de suas ações em busca do desenvolvimento local sustentável de seu território.

É imprescindível compreender como ocorre às dinâmicas econômicas e solidárias no dia a dia das comunidades ribeirinhas da Amazônia marajoara, uma vez que esse entendimento irá contribuir para o melhor encaminhamento das possibilidades e limites que permeiam a estruturação e a gestão de empreendimentos solidários no âmbito do Marajó.

A Economia Solidária configura-se como uma alternativa de desenvolvimento, por meio da emancipação social de amplo espectro de ação, tal qual um antídoto ao apetite voraz do sistema capitalista convencional que persegue a maximização do lucro a qualquer preço, onde o óbvio deveria ser a maximização do benefício social. De acordo com Singer (2002), a Economia Solidária pode ser entendida como outro modo de produção e as liberdades individuais devem satisfazer os interesses da coletividade.

Em uma abordagem mais contemporânea, pode-se afirmar ainda que a economia solidária se encontra em transição, especialmente no Brasil, e toma formas e vertentes diferenciadas, tais como, as abordagens do empreendedorismo solidário, empreendedorismo social, empreendedorismo sustentável e empreendedorismo comunitário. Seus princípios também estão presentes em projetos de responsabilidade social e ambiental coorporativos. Enfim, ela está em todas as iniciativas que preservam os princípios da cooperação, autogestão, equidade, solidariedade, sustentabilidade, 
valorização do meio ambiente e do saber local, e fundamentalmente em todas as atividades do trabalho humano, por meio da associação voluntária de pessoas que visem o apoio mútuo de suas atividades. Embora seja no modelo cooperativo de organização que ela melhor se identifica.

Luzio dos Santos (2014), acrescenta a discussão quando afirma que a economia solidaria integra diferentes iniciativas organizacionais, porém, tem no cooperativismo o seu principal modelo de funcionamento e busca resgatar a sua identidade original.

O Plano Nacional de Economia Solidária (2015), estabelece uma compreensão mais ampliada do conceito de economia solidária. Essa alternativa de desenvolvimento inclui formas de organização econômica de produção, prestação de serviços, comercialização, finanças e consumo. Tendo como base o trabalho associado, na perspectiva da autogestão, na propriedade coletiva dos meios de produção, na cooperação e na solidariedade. São atividades econômicas sendo plenamente operacionalizadas por cooperativas, associações, empresas recuperadas por trabalhadores em regime de autogestão, grupos solidários informais, redes de cooperação em cadeias produtivas e arranjos econômicos locais ou setoriais, bancos comunitários de desenvolvimento e fundos rotativos. Portanto, evidencia-se uma expansão em sua compreensão e prática.

Diante do exposto, decidiu-se estudar tal fenômeno social. Para tanto, definiu-se como questão problematizadora identificar se as iniciativas econômicas solidárias, bem como suas redes de colaboração, implementadas no âmbito do território do Marajó, têm reais condições de obter bons resultados considerando as grandes limitações presentes nesse espaço geográfico.

A hipótese submetida à confirmação ou contestação é de que a economia solidária é uma estratégia capaz de produzir efeitos positivos em todo o mundo e não seria diferente no caso do território do Marajó. Entretanto, esse modelo de negócio e ao mesmo tempo de filosofia de vida, traz consigo importantes desafios em sua implantação, em especial em um lugar como a Amazônia, com suas complexidades e limitações no que tange aos aspectos políticos, econômicos e sociais.

Pressupõe-se, contudo, que a comunidade pesquisada se encontra em plena construção de uma cultura solidária, mas que ainda requer dar um salto de qualidade no amadurecimento e operacionalização de seus projetos, no efetivo acesso à novos mercados, e no aprimoramento e operacionalização de suas redes de colaboração 
solidária dentro e fora do PEAEX Acutipereira, para assim atingir sua emancipação social e o bem-estar coletivo.

O objetivo da pesquisa se concentrou em apresentar iniciativas econômicas solidárias de relevância social em andamento na Amazônia marajoara que se mostram promissoras na busca da melhor gestão dos recursos naturais e desenvolvimento local sustentável, bem como avaliar as dinâmicas das redes de colaboração solidárias existentes e potenciais, e suas reais possibilidades e limites para o sucesso.

O presente estudo advém de esforço acadêmico proveniente de pesquisa científica que se encontra em evolução no âmbito de programa de mestrado profissional. No presente estudo, procurou-se realizar além da apresentação das importantes iniciativas econômicas solidárias em andamento no Marajó, também uma análise quanto às relações colaborativas entre as diversas comunidades do PEAEX Acutipereira e assentamentos adjacentes.

\section{METODOLOGIA}

A área de observação empírica do presente estudo foi a comunidade ribeirinha Santo Ezequiel Moreno, localizada em um Projeto Estadual de Assentamento Agroextrativista (PEAEX), no município de Portel, estado do Pará.

Para o desenvolvimento do estudo de caso, os procedimentos metodológicos utilizados foram a pesquisa de modalidade bibliográfica e documental, com o uso do método qualitativo, com abordagem do tipo exploratória. Diante do exposto, buscou-se descrever as características de determinada população ou fenômeno e o estabelecimento de relações entre as variáveis. Complementarmente, foram realizadas visitas in loco para melhor subsidiar as análises necessárias.

O estudo de caso possibilitou a manifestação de falas e saberes de trabalhadores agroextrativistas que vivenciam os fatos e as relações sociais e produtivas presentes na área de estudo. Portanto, conforme defende Gil (2002), na presente pesquisa buscou proporcionar uma visão global do problema e ao mesmo tempo identificar possíveis fatores que o influenciam ou são por ele influenciados.

Para a coleta de dados utilizou-se como instrumentos de pesquisa entrevistas livres e semiestruturadas e a observação sistemática em um conjunto de entrevistados escolhidos por meio do critério da efetiva participação direta nas inúmeras atividades 
solidárias desenvolvidas no âmbito da comunidade pesquisada. Com base nesse critério, entrevistou-se as principais lideranças da comunidade Santo Ezequiel Moreno, sendo eles líderes que compõem uma coletividade organizada e se identificam como agroextrativistas. São sujeitos que efetivamente protagonizam as relevantes transformações sociais pelas quais vem passando as comunidades do PEAEX Acutipereira.

\section{DISCUSSÃO E RESULTADOS}

Os resultados obtidos foram organizados de forma a apresentar de maneira sucinta o que vem ocorrendo em um caso de relevância social no Marajó. O primeiro eixo de análise concentrou-se na abordagem do histórico da comunidade pesquisada. Em seguida apresenta-se os principais projetos econômicos solidários em andamento no âmbito da comunidade e suas redes de colaboração solidárias em plena construção no PEAEX Acutipereira e demais assentamentos vizinhos.

\subsection{A Comunidade Santo Ezequiel Moreno - Portel (PA)}

O estudo tomou como espaço geográfico a comunidade rural Santo Ezequiel Moreno, localizada no município de Portel, estado do Pará, mais especificamente no Projeto Estadual de Assentamento Agroextrativista (PEAEX) denominado Acutipereira, que possui área de 65.640,0977 hectares, para o assentamento de 368 (trezentas e sessenta e oito) famílias.

Atualmente na comunidade habitam 34 famílias, com aproximadamente 160 moradores que vivem principalmente da manipulação de produtos oriundos da floresta, e suas atividades são essencialmente realizadas de forma harmoniosa com o meio ambiente que os cercam. 


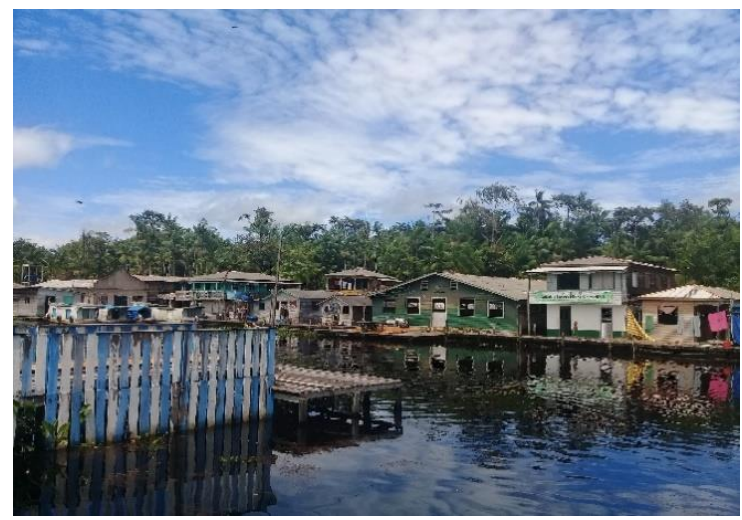

Fonte: Registro do autor

Durante a pesquisa de campo, evidenciou-se que os fundamentos requeridos para se enquadrar em uma realidade de cooperação, autogestão, equidade, solidariedade e sustentabilidade, estão presentes no dia a dia de seus moradores e em sua relação com a gestão sustentável dos recursos naturais, de modo a buscar de forma permanente o bemestar individual, comunitário, social e ambiental em suas relações humanas (LUZIO DOS SANTOS, 2014).

É importante mencionar que o governo do Estado do Pará, por meio do Decreto Estadual ํㅡ 2.012, de 20 de março de 2018, criou o Projeto Estadual de Assentamento Agroextrativista (PEAEX), denominado Acutipereira, no território da antiga Gleba Acutipereira, para assegurar direitos territoriais aos agroextrativistas. 


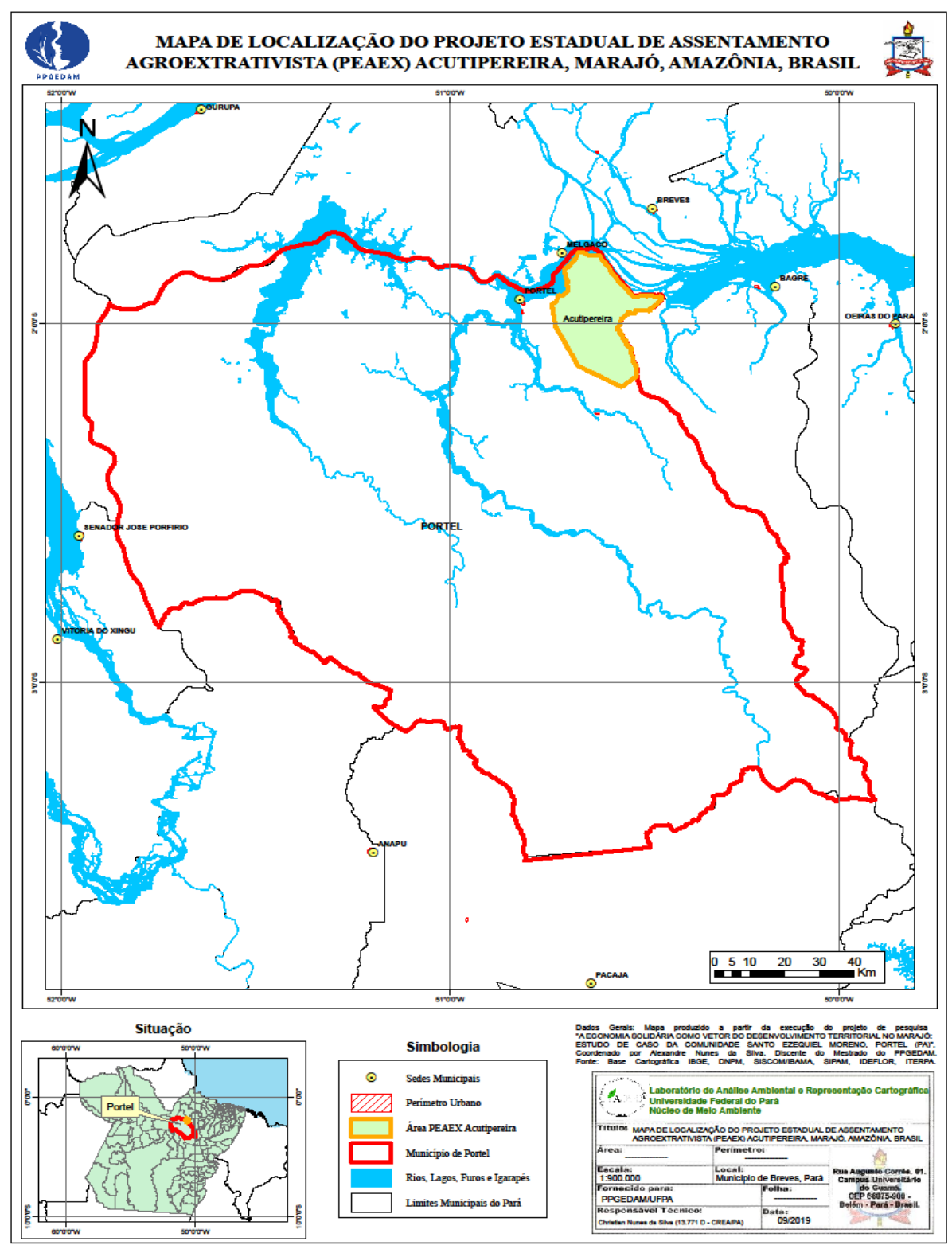

Fonte: Pesquisa de Campo

Consolidou-se assim o processo de regularização fundiária e ambiental em 65.640 hectares, que beneficiou diretamente 368 famílias. Um excelente resultado alcançado por intermédio de intensa mobilização social em busca da garantia de direitos pelo uso da terra e maior acesso a políticas públicas. Atitudes legitimas e emanadas das bases populares, em meio a uma trajetória marcada por lutas, mortes e trabalho associativo, conforme contextualização histórica a seguir.

Nas décadas de 1980 e até meados do ano 2000 a região foi marcada pela intensa exploração dos recursos naturais, cuja atividade madeireira, a exploração do palmito e a pecuária intensiva, ocasionaram profundos impactos ambientais em toda a região 
marajoara (FASE, 2006). Essa também foi a realidade enfrentada pelas comunidades do rio Acutipereira, até a ocorrência de um fato que deu destaque nacional e internacional para essa região.

No ano de 2004, houve um surto endêmico de raiva humana nas localidades do rio Acutipereira, proveniente da transmissão via mordedura de morcegos hematófagos. Foram registradas as mortes de 16 comunitários (EID, 2004). Esse fato fez com que os moradores das comunidades desse rio refletissem sobre os impactos da ação do homem sobre o meio ambiente e sua repercussão até mesmo no comportamento dos animais (como o morcego), pois a degradação da floresta obrigou a busca desses animais por novos habitats e novas fontes de alimentos. A partir desse lamentável acontecimento, deram início a uma diversidade de ações, promovidas e desencadeadas com 0 protagonismo local e suporte de órgãos públicos, organizações não governamentais, governo municipal, igrejas, agentes de financiamento e instituições de ensino e pesquisa.

Estabeleceu-se, portanto, um cenário de mudança de atitude que possibilitou, ainda em 2004, a criação da Associação dos Trabalhadores Agroextrativistas do Rio Acutipereira (ATAA), entidade que representa os moradores de Santo Ezequiel Moreno e de outras comunidades da região do baixo Acutipereira. Passo importante que possibilitou o planejamento e criação de diversas iniciativas inovadoras com reais poderes de transformação socioambiental.

A partir de 2005 observou-se o interesse crescente dos agroextrativistas pela legitimação de seus direitos fundiários e outras iniciativas que buscariam 0 desenvolvimento territorial sustentável. Em entrevista com uma das principais lideranças comunitárias e grande agente de desenvolvimento local do Marajó, verificou-se como surgiu os primeiros movimentos que despertaram esse interesse.

Em junho 2005, houve o primeiro seminário com o tema da regularização fundiária, muito bom. Foi um marco e a partir daí tivemos outra visão. Tivemos várias experiências, como o reflorestamento, o manejo florestal e começamos a trabalhar essas questões, tinham poucas lideranças que acreditavam. Não foi fácil, foi uma inspiração de Deus. Alguns desistiram, mas não perdemos a esperança, hoje conseguimos o título da terra e mais qualidade de vida. Falo isso com muito orgulho, mas no caso do PEAEX foi pressão, foi pressão mesmo. É um jogo político e as lutas não são de agora, são lutas de 20 anos (Teofro Gomes Lacerda - Liderança Comunitária).

Evidencia-se, portanto, que decorrer de aproximadamente 20 anos, em meio a vivência de acontecimentos com impactos negativos para o meio ambiente e 
principalmente para as pessoas (como o surto de raiva humana em 2004), possibilitou que nos dias atuais os agroextrativistas compreendam que a saída para a melhoria da qualidade de vida perpassa pelo incremento da renda familiar, pela busca por melhores condições de vida e pelo respeito a natureza, e isso só ocorre a partir de um intenso processo de organização e controle social. Deste modo, consolidou-se o assentamento.

Em 2018, deu-se iniciou a construção o Escritório de Economia Solidária e Sustentabilidade da Comunidade Santo Ezequiel Moreno - PEAEX Acutipereira. Iniciativa popular que deixa claro a perspectiva acerca do modelo de desenvolvimento territorial que se busca atingir no âmbito dessa localidade, o bem estar individual e comunitário, permeada de valores que buscam atender às necessidades e os desejos materiais e de convivência, mediante mecanismos de democracia participativa e de autogestão, visando a emancipação e o bem estar individual, comunitário, social e ambiental (SINGER, 2002).

Outras iniciativas solidárias importantes estão em curso no âmbito da comunidade pesquisada.

\subsection{O Fundo Solidário Açaí: A Tecnologia Social Emancipatória}

A partir dos esforços coletivos da ATAA, no ano de 2012 foi criado o Fundo Solidário Açaí. Trata-se de uma Tecnologia Social (TS), certificada e premiada pela Fundação Banco do Brasil no ano de 2017, e também premiada pela Caixa Econômica Federal com o Prêmio Melhores Práticas em Gestão Local, no mesmo ano.

Miranda e Potiguar (2017), conceituam o Fundo Florestal Comunitário Familiar (FFCF), como reservas econômicas coletivas formadas a partir da comercialização de bens e serviços florestais para o bem viver das famílias e comunidades agroextrativistas. Os objetivos do Fundo Solidário Açaí foram norteados para o enfrentamento dos problemas de infraestrutura comunitária e socioprodutiva, para favorecer a permanência dos cidadãos agroextrativistas em seu território, como provedores de conhecimento tradicional associado à cultura do açaí, com boa qualidade de vida e capacidade de resistência.

A tecnologia social é operacionalizada a partir da arrecadação pecuniária realizada ao longo da safra do açaí comercializado pelos agroextrativistas. Com a contribuição de $\mathrm{R} \$ 2,00$ (dois reais) por cada lata de açaí vendido, forma-se uma poupança coletiva que é convertida em benfeitorias à comunidade (MIRANDA; POTIGUAR, 2017). Os recursos 
financeiros são repassados a tesouraria da ATAA e a aplicação desses recursos é votada em assembleia. No ano de 2018 foi contabilizado uma poupança no montante de $\mathrm{R} \$$ 13.444,00. Portanto, o fundo caracteriza-se como uma importante alternativa econômica para o coletivo de agroextrativistas.

Destaca-se algumas ações de maior relevância realizadas a partir da iniciativa do Fundo Solidário Açaí: investimento na ampliação da sede da ATAA; estruturação do sistema de abastecimento de água (700 metros de encanamento); suporte às lideranças comunitárias em viagens para a participação em capacitações e intercâmbios; investimentos em outros produtos agrícolas e agroflorestais como hortaliças, legumes, mandioca, fruticultura (bacuri, taperebá, abacaxi), e no próprio manejo de açaizais e de espécies florestais como a andiroba; reforma da capela local; fortalecimento da agricultura familiar para a expansão em mercados institucionais do Programa de Aquisição de Alimentos (PAA), Programa Nacional de Alimentação Escolar (PNAE).

Cabe destacar que a primeira benfeitoria proveniente do esforço coletivo solidário, fora a construção de uma ponte e passarelas de madeira, com mais de 690 metros de extensão, que interligam todas as casas umas às outras, até a área de plantio das famílias (terra firme). Estrutura à primeira vista simples e básica para uma realidade urbana, todavia, mostra-se uma obra importante para a realidade ribeirinha marajoara, que trouxe grandes benefícios para a qualidade de vida e o fortalecimento das relações de solidariedade entre os agroextrativistas, pois a partir de então, passa a existir uma ligação física entre todas as residências, que as unem e as levam ao trabalho (casas de farinha, caça, produção agrícola familiar, extrativismo), e ao lazer (campo de futebol). Enfim, levam à caminhos que fortalecem os vínculos sociais solidários e cooperativos.

\subsection{A Miniagroindústria Boa União e o Potencial Cooperativo}

Outra iniciativa popular solidária importante na Comunidade Santo Ezequiel Moreno fora a construção da miniagroindústria de beneficiamento de frutas nativas Boa União, que em 2020 dar início as suas atividades produtivas, a qual possibilitará girar a roda da cadeia de valor na comunidade. O principal produto florestal será o açaí de

várzea (Euterpe oleracea). A perspectiva é escoar a produção para o mercado consumidor da área urbana do município de Portel, bem como destinar à Programas de Governo, tais como o Programa de Aquisição de Alimentos (PAA) e o Programa Nacional 
de Alimentação Escolar (PNAE). Assim os agroextrativistas irão se inserir na cadeia produtiva de seu território e assumirão as funções de coleta, processamento e comercialização do fruto, e desta forma irão aferir maior renda e qualidade de vida.

O projeto encontra-se paralisado, pois estava aguardando o início do fornecimento de energia elétrica por parte da empresa de distribuição - Centrais Elétricas do Pará (CELPA), que fora parcialmente efetivado em agosto de 2019. Essa demora ocasionou tensões entre os agroextrativistas e a concessionária de energia elétrica, tendo em vista a necessidade urgente de operacionalizar a iniciativa planejada coletivamente e arduamente construída pelos agroextrativistas organizados por meio da solidariedade.

Tomando como exemplo esse caso específico, observa-se o descompasso do poder público no atendimento de demandas básicas junto à sociedade civil organizada. Em visita in $10 c o$, verificou-se que está em fase de discussão e planejamento a implementação de uma cooperativa para operacionalizar esse empreendimento solidário, além dos demais projetos econômicos solidários.

O ramo de atuação que mais se molda a realidade estudada é o ramo agropecuário, pois no futuro empreendimento coletivo, haverá a união solidária dos agroextrativistas para a realização de etapas indispensáveis na cadeia produtiva do açaí, que vão desde a compra de insumos até a colheita, armazenamento, processamento e comercialização da produção. Dessa forma, nota-se um esforço no sentido de expandir a eficiência das iniciativas econômicas da comunidade, todavia, o intuito é manter-se dentro da filosofia solidária e isso será possível por intermédio de uma cooperativa, conforme defende Luzio dos Santos (2014).

\subsection{A Cozinha Agroextrativista laçá e o Protagonismo Feminino}

Inaugurada em setembro de 2018, a Cozinha Agroextrativista laçá representa mais uma importante iniciativa econômica solidária, desta vez com o protagonismo essencialmente feminino. Trata-se de um projeto proveniente da organização comunitária por meio da ATAA, Fundo Solidário Açaí, Associação dos Moradores Agroextrativistas do Assentamento Acutipereira (ASMOGA), em parceria com o Instituto Internacional de Educação do Brasil (IEB) e apoio financeiro do Fundo Socioambiental Caixa, o qual foi responsável pelo financiamento de todos os equipamentos da cozinha. 
Esta iniciativa é liderada pelo projeto Mulheres Marajoaras: inclusão produtiva e sustentabilidade, gerido pelas mulheres da comunidade Santo Ezequiel Moreno. É importante frisar que toda a infraestrutura em alvenaria fora construída a partir da mobilização popular e os alimentos produzidos estão sendo fornecidos à escola municipal da comunidade, por intermédio do Programa Nacional de Alimentação Escolar (PNAE). A perspectiva é atender a mais três escolas, além de produzir alimentos sob encomenda destinados à venda direta local e para outras comunidades, bem como para eventos e feiras livres do município de Portel.

O objetivo central desta iniciativa é fortalecer as experiências solidárias de inclusão produtiva sustentável de famílias agroextrativistas do Marajó, com base no protagonismo das mulheres. Além de promover ações que visem o fomento à capacitação para a agregação de valor aos produtos da agricultura familiar e o acesso à mercados institucionais.

\subsection{O PEAEX Acutipereira e sua Rede de Colaboração Solidária}

Ao observar a realidade concreta da região do Marajó das águas e das florestas, como apresentado no caso da comunidade Santo Ezequiel Moreno, constata-se que existem iniciativas solidárias autogestionárias promissoras, entretanto, apresentam-se apartadas pelas grandes distâncias fluviais presentes em todo o território, fato que dificulta sobremaneira as atuais e eventuais conexões solidárias que se constituem no Marajó. Contudo, deve-se considerar que todas as relações sociais se encontram interconectadas como nunca antes, e diante dessa realidade, investir na sinergia entre as diversas iniciativas solidárias de produção e consumo a partir de redes colaborativas de apoio mútuo, certamente, configura-se como a chave para o desenlace do efetivo desenvolvimento territorial do Marajó.

A economia solidária deve se livrar das amarras das contradições do modo de produção e consumo dominantes e buscar transcender o problema da dispersão territorial e setorial, realidade em que cada um compete sozinho nos mercados onde vende e nos que compra. Esses empreendimentos solidários teriam que se agregar num todo economicamente consistente, capaz de oferecer a todos os que a desejassem a oportunidade de trabalhar e viver cooperativamente (SINGER, 2002). 
Nesse sentido, Mance (2000) colabora na reflexão ao acrescentar o conceito de redes de colaboração solidária. A lógica das redes parte do princípio de que os empreendimentos solidários que operam isoladamente tendem a fracassar devido à concorrência desleal promovida pelo sistema capitalista. As redes funcionam como um sistema aberto, autônomo que se autorreproduz, pois estão interligadas de uma maneira que englobam os empreendimentos solidários distintos e complementares, gerando um complexo sistema que inclui diversas unidades produtivas, distributivas e comerciais. Deste modo, aproxima-se o consumo da produção.

Sua dinâmica consiste em um todo solidário e sinérgico, onde, por exemplo, o bem final que é produzido por uma célula da rede, deverá demandar insumos que são produzidos por uma célula dentro da própria rede, gerando e fortalecendo a cooperação entre todas as células do sistema. Mance (2000) ainda defende que as redes de colaboração devem ser construídas de baixo para cima, portanto, emanadas das bases populares, sem a interferência do governo ou de empresas capitalistas. Desta forma, temse mais garantias de manter sua independência e uma governança popular com liberdade e capacidade de gestão própria.

O autor também destaca que para viabilizar o modelo organizacional com ênfase nas redes de colaboração solidária é necessário desenvolver um processo educativo e informativo que crie uma cultura do consumo solidário. Esse modelo de consumo busca atender as necessidades e desejos de seus consumidores, visando seu bem viver pessoal e, busca produzir o bem estar dos trabalhadores envolvidos com a produção, distribuição e comercialização daquele produto ou serviço, mantendo o equilíbrio dos recursos naturais e contribuindo para a construção de sociedades mais justas e solidárias (MANCE, 2000).

Com base nesse contexto, buscou-se analisar a realidade concreta do PEAEX Acutipereira. E, diante disso, constatou-se a consecução de esforços no sentido de promover a ativação de uma rede de colaboração solidária no âmbito do PEAEX Acutipereira, visto que se observa um fluxo de produção e consumo de forma consistente e sinérgico, com diferentes níveis de relações colaborativas. Por enquanto informais, essa rede é baseada em contratos de confiança e colaboração entre os agroextrativistas, com apoio e resultados satisfatórios mútuos. Contudo, tal informalidade poderá ser substituída por uma ação mais organizada, por intermédio da cooperativa que se encontra em fase de planejamento. 
É importante refletir que a conversão da personalidade jurídica da atual associação para uma cooperativa irá permitir o acesso mais facilitado à mercados mais promissores, tais como a comercialização ampliada junto ao Programa Nacional de Alimentação Escolar (PNAE) e o Programa de Aquisição de Alimentos (PAA). Portanto, evidencia-se que essa transição tem o potencial de fortalecer as conexões da rede de colaboração solidária entre as comunidades dentro e fora do PEAEX Acutipereira e, consequentemente, abrirá novos mercados e grandes possibilidades de atuação, em especial para a comunidade Santo Ezequiel Moreno.

Para facilitar a compreensão acerca da operacionalização da rede de colaboração solidária presente no âmbito do PEAEX Acutipereira, destaca-se a tabela 1.

Tabela 1: Relações de Produção e Consumo Solidário entre as comunidades do PEAEX Acutipereira

\begin{tabular}{|c|c|}
\hline Comunidade & Colaboração - Produção e Consumo \\
\hline Santo Ezequiel Moreno ${ }^{\star \star \star}$ & Açaí / Peixe / Macaxeira / Farinha / Abobora \\
\hline $\begin{array}{l}\text { N. Sra. Perpétuo Socorro }- \text { Rio Campina } \\
\text { Maripajó }\end{array}$ & Camarão / Açaí / Peixe / Mamão / Hortaliças \\
\hline São Jorge ${ }^{\star \star \star}$ & Farinha / Açaí / Macaxeira / Abobora / Milho \\
\hline São Benedito*** & Polpa de Fruta / Farinha / Bacuri / Açaí / Cupuaçu \\
\hline N. Sra. Livramento*** & Açaí / Farinha / Macaxeira / Bacuri / Milho / Peixe \\
\hline Menino Deus** & Farinha \\
\hline N. Sra. Aparecida** & Bacaba / Açaí / Farinha / Macaxeira / Abacaxi / Caju \\
\hline São Bento** & Açaí \\
\hline N. Sra. Perpétuo Socorro - Rio Irapiuna** & Açaí / Farinha / Macaxeira \\
\hline Deus Proverá** & Farinha \\
\hline Santa Rosa** & Açaí / Farinha \\
\hline São Tomé (Quilombo) ${ }^{\star \star}$ & Farinha / Açaí / Macaxeira / Abobora / Milho \\
\hline São Miguel** & Patauá, / Milho / Abobora / Farinha \\
\hline Monte Betel - Igarapé Mocajatuba** & $\begin{array}{l}\text { Abacaxi / Farinha / Macaxeira / Polpa de Frutas / } \\
\text { Caju / Bacaba }\end{array}$ \\
\hline Monte Betel - Rio Acutipereira** & Patauá / Farinha \\
\hline Monte Betel - Rio Jaguarajó ${ }^{\star \star}$ & Farinha / Milho / Abobora \\
\hline Jerusalém - Rio Ajará* & Farinha / Milho / Macaxeira \\
\hline Jerusalém - Beiradão* & Farinha / Cupuaçu / Mamão / Abacaxi \\
\hline Vila Paraíso* & Patauá / Farinha / Milho / Abobora \\
\hline Jeová Samá* & Camarão / Açaí / Farinha \\
\hline
\end{tabular}

Fonte: Pesquisa de Campo 
A partir da análise da tabela 1, é possível notar que as comunidades com maior colaboração solidária em rede são as comunidades Santo Ezequiel Moreno, Nossa Senhora do Perpétuo Socorro do Rio Campina Maripajó, São Jorge, São Benedito e Nossa Senhora do Livramento. Juntas. Essas comunidades mantêm uma relação de consumo e produção mútua, que permite a circulação produtos florestais valiosos, tais como: açaí, farinha, peixe, além de diversos tipos de frutas, legumes e hortaliças. As demais comunidades atualmente demonstram um nível de colaboração solidária, considerado razoável e potencialmente promissor.

Em entrevistas em campo, evidenciou-se questões importantes quantos aos aspectos de consumo e produção, com relevante potencial econômico: a) As comunidades Santo Ezequiel Moreno e Santa Rosa detém a mais forte produção de açaí e peixe do assentamento; b) As comunidades Perpétuo Socorro do Rio Campina Maripajó e a Jeová Samá mantêm relações de colaborações produtivas intensas através do camarão e do açaí, produtos altamente demandados em toda a região amazônica; c) As comunidades Monte Betel - Rio Acutipereira, São Miguel e Vila Paraíso detêm forte produção de patauá (Jessenia bataua), palmeira originária da Amazônia, que produz um fruto comestível rico em óleo de alta qualidade que aproxima-se do azeite de oliva (CAVALCANTE, 1991).

Essas relações de consumo e produção devem ser melhor exploradas, de modo a possibilitar maior geração de trabalho, renda e melhor qualidade de vida a todos os agroextrativistas envolvidos. Para tanto, é necessário colocar em prática os princípios da intensividade e da extensividade defendidos por Mance (2000).

As comunidades do PEAEX Acutipereira devem envidar esforços para primeiramente ampliar a intensividade entre as comunidades, isso significa que cada comunidade da rede deve procurar atingir e envolver o maior número de pessoas dentro do assentamento. Essa prática irá permitir o surgimento de outras pequenas iniciativas articuladas entre si dentro da região, e conectadas a uma rede geral de colaboração com sede na comunidade Santo Ezequiel Moreno.

Observa-se na fala de liderança comunitária, quando questionado sobre a existência de conexões em termos de produção e consumo, que esse processo se encontra em andamento.

Sim, existem conexões entre as comunidades. Por exemplo, em um evento recentemente, a banana veio lá do assentamento Jacaré Puru, lá do 
Pacajá. O abacaxi veio lá da comunidade Menino Deus. Copaíba a gente consegue lá da ATAAP (Associação dos Trabalhadores Agroextrativista do Alto Pacajá), lá tem uma produção bem forte do óleo de copaíba. Açaí é nosso, o açaí é mais nós que temos, o potencial maior de açaí é o Acutipereira. Hoje tá iniciando um processo de capacitação de áreas de manejo de açaizal dos outros assentamentos (Nilson Corrêa da Silva Presidente da ATAA).

Portanto, observa-se a busca pela ampliação das relações internas de colaboração de forma a intensificar permanentemente as relações de produção e consumo entre as comunidades com fortes e medianas relações colaborativas. Além de procurar efetivamente integrar as comunidades atualmente consideradas potencialmente promissoras em termos de colaboração solidária. Neste caso as comunidades Jerusalém - Rio Ajará, Jerusalém - Beiradão, Vila Paraiso e Jeová Samá.

Quanto ao princípio da extensividade, refere-se à necessidade de expandir a rede para outros territórios, e assim permitir o surgimento e desenvolvimento de novas unidades colaborativas. Assim a abrangência da rede será ampliada e fortalecida em seu conjunto. Neste caso, a ampliação será no âmbito dos assentamentos vizinhos ao Acutipereira - PEAEX Acangatá, Auto Camarapi e Jacaré-Puru e futuro PEAEX Joana Peres II. Cada comunidade integrante desses assentamentos agroextrativistas, em uma ação sinérgica, tem o potencial de perseguir seus objetivos, fortalecendo-se reciprocamente em sua identidade agroextrativista em prol de uma sociedade mais justa e equilibrada.

Ao considerar a iniciativa da Miniagroindústria Boa União, nota-se mais um projeto que efetivamente irá buscar o fortalecimento da rede de colaboração solidária do assentamento. Possivelmente essa iniciativa se tornará algo maior e mais extenso no território do PEAEX Acutipereira e assentamentos adjacentes, visto que se planeja implementar uma Central de Distribuição do açaí de várzea manejado pelo agroextrativistas marajoaras. A fala da liderança comunitária revela os esforços para a promoção da ativação da rede de colaboração a partir do beneficiamento e comercialização do açaí.

Em relação ao comércio do açaí teremos uma central de distribuição. Não será só a ATAA na produção do açaí, mas terá uma aliança entre ATAA, ASMOGA, Associação do Anapú, Associação do Pacajá e do Camarapi. A central será uma associação de associações, onde vai pegar o açaí de todo mundo e vai distribuir. Ou seja, o comunitário vai se preocupar em produzir e para comercializar terá uma central que vai se preocupar com isso. A ideia seria mandarmos o açaí para Belém, que é um açaí bom, com qualidade, mas acaba não chegando lá porque não tem uma organização 
de uma central para distribuir isso. A central seria instalada na cidade de Portel por uma questão de logística (Nilson Corrêa da Silva, Presidente da ATAA).

No que tange a Cozinha Agroextrativista laçá, observa-se que o empreendimento solidário busca produzir alimentos com a utilização de matérias primas exclusivamente provenientes dos agroextrativistas assentados no Acutipereira e demais assentamentos adjacentes. Destaca-se as falas de importantes agentes de desenvolvimento comunitário.

Quando tem eventos aqui, a cozinha pega a demanda de produtos para o evento, então a gente vê o que a comunidade tem e o que a comunidade não tem. O que a comunidade tem aqui, ela produz e entrega, mas o que ela não tem, a gente vai ter que buscar em outras comunidades. Isso já não traz benefícios só para nós, mas para outras comunidades vizinhas. A gente vê que é uma coisa que não vai gerar resultado só para dentro da nossa comunidade, mas sim para a coletividade (Sônia do Socorro de Oliveira Almeida, Coordenadora da Cozinha Agroextrativista laçá).

De acordo com a agroextrativista, Sr. ‥ Maria Cláudia dos Santos Baia, "o projeto da cozinha é isso, é pegar os produtos das diversas comunidades, tanto de dentro quanto fora do assentamento, produzir na Cozinha laçá e vender na cidade e para as escolas".

É importante destacar que o ano de 2019 foi marcado pelo início de um projeto que tem o potencial de intensificar as relações solidárias em todo o Marajó, trata-se do Manejaí e Companhia. Por meio dessa iniciativa popular, com sede na comunidade Santo Ezequiel Moreno, será possível dar continuidade as ações do Centro de Referência em Manejo de Açaizais no Marajó (MANEJAí), que se encontra em fase de conclusão e foi conduzido no âmbito do Projeto Bem Diverso, por meio de parcerias entre a Empresa Brasileira de Pesquisa Agropecuária (EMBRAPA), e o Programa das Nações Unidas para o Desenvolvimento (PNUD). O Manejaí e Companhia será um canal de formação para as boas práticas de manejo de mínimo impacto de açaizais nativos nas florestas de várzeas e outras culturas marajoaras, e dará continuidade a missão de contribuir para o manejo sustentável da biodiversidade, assegurando os modos de vida dos agroextrativistas marajoaras, gerando renda e melhorando a qualidade de vida.

Todo e qualquer trabalho, a gente não pensa só em nós. No Manejaí e Companhia, vamos abrir espaço para as outras comunidades. Em cada rio vamos fazer 2 cursos e formar entre 25 a 30 facilitadores em cada curso. Vamos acompanhar para saber se estão colocando em prática. Cada um deverá manejar 1 hectare de açaí (Teofro Gomes Lacerda, Coordenador do Manejaí e Companhia). 
Observa-se que o coordenador do Manejaí e Companhia, apresenta uma abordagem ampla e integrada da ação que será desenvolvida pelo projeto.

\section{CONSIDERAÇÕES FINAIS}

Com base nos preceitos de Mance (2000, 2002), o estudo de caso aponta uma possibilidade econômica viável para o território da Amazônia Marajoara. Trata-se da ativação de uma rede de colaboração solidária, que se corretamente estimulada, será praticado o consumo solidário entre as comunidades dentro o fora do PEAEX Acutipereira, que futuramente irá gerar um excedente que permitirá a criação de novas unidades produtivas e consumidoras, a partir da comercialização de toda a sua produção. Essa união irá atender a uma demanda ainda maior de produtos e serviços em um movimento autossustentável de expansão. Trata-se de um ciclo virtuoso de desenvolvimento econômico, permeado pela solidariedade entre povos organizados, e que promove o fortalecimento de sua identidade agroextrativista.

Observa-se que a relação trabalho-renda que se proporciona por intermédio da economia solidária de fato está ocorrendo no território da Amazônia Marajoara, mesmo que de forma incipiente. É evidente que a comunidade Santo Ezequiel Moreno exerce grande poder de governança territorial e vem desenvolvendo importantes ações para o incremento de sua rede colaboração solidária que a diferencia e a coloca em um patamar importante em termos de desenvolvimento local. Visto que seus agroextrativistas desenvolvem estratégias de organização social que buscam a cooperação, autogestão, equidade, solidariedade e a sustentabilidade em suas iniciativas coletivas, e vem atuando com o objetivo de efetivamente dar o salto de qualidade necessário para o alcance de sua emancipação social e o bem estar coletivo.

Essas ações contam com a contribuição de uma diversidade de parceiros institucionais, mas sua dinâmica se movimenta principalmente a partir da dedicação de cada um dos seus moradores, verdadeiros agentes colaborativos que integram uma rede cada vez mais consolidada de solidariedade em busca do desenvolvimento territorial.

As iniciativas solidárias analisadas pelo estudo de caso - Fundo Solidário Açaí, a Cozinha Agroextrativista laçá, a Miniagroindústria e mais recentemente o Projeto Manejaí, servem com indutores conectivos para a intensividade e extensividade da rede de 
colaboração, previstas por Mance (2000, 2002). A Cozinha laçá, fortalece o fluxo produtivo e comercial dos produtos florestais provenientes da agricultura familiar dos assentamentos. A Miniagroindústria Boa União, brevemente irá colaborar no projeto da central de distribuição do açaí de várzea manejado, proveniente das diversas comunidades dentro e fora do assentamento. O Manejaí e Companhia irá promover o intercâmbio de saberes e maior capacidade produtiva do açaí de várzea de forma absolutamente sustentável. Portanto, nota-se que esses projetos colaborativos também exercem a função de reunir as comunidades do PEAEX Acutipereira e demais assentamentos da região e revelam-se mais do que possibilidades, soluções concretas para a consolidação de uma rede de colaboração solidária para o desenvolvimento territorial da Amazônia Marajoara.

Para o efetivo sucesso das redes de colaboração solidárias, deve-se considerar aspectos importantes, tais como: a logística para a consecução eficiente do fluxo de produtos entre as diversas comunidades assentadas. As grandes distâncias entre as comunidades e a falta de infraestrutura de transporte fluvial e terrestre, que frequentemente inviabilizam a colaboração solidária. Algumas comunidades não possuem energia elétrica, e diante disso não há como fornecer grandes quantidades de produtos, devido sua perecibilidade, tais como o açaí.

Ainda, deve-se observar e atender as exigências de cada processo produtivo, tais como: manter uma escala produtiva em quantidade, frequência e qualidade suficientes para atender as demandas dos mercados futuros, dentro e fora do PEAEX Acutipereira. Outro fator limitante que deve ser mitigado é a resistência de algumas lideranças comunitárias dentro do PEAEX Acutipereira. Evidencia-se uma espécie de desconfiança atrelada à aspectos culturais e políticos que dificultam a cooperação para o bem estar coletivo. Essa resistência se materializa por meio da falta de apoio na operacionalização do trabalho colaborativo, bem como a ausência de iniciativas para a promoção da governança territorial por meio de uma mobilização social permanente.

Por fim, conclui-se que apesar dos pontos que ainda merecem aprimoramentos, é evidente que o caso estudado revela os grandes avanços em termos da ativação de uma ampla e consistente rede de colaboração solidária sendo tecida no âmbito da Amazônia Marajoara, o que demonstra que os fundamentos econômicos solidários, de fato, tem o potencial de transformar a realidade das pessoas de forma mais justa e equilibrada. 


\section{REFERÊNCIAS}

BRASIL. Plano Nacional de Economia Solidária. Ministério da Economia. Conselho Nacional de Economia Solidária, 2015.

CALVALCANTE, Paulo B. Frutas comestíveis da Amazônia. - Belém: Museu paraense Emilio Goeldi, 1991.

Cozinha Agroextrativista laçá. Receitas da Culinária Agroextrativista -Organização: IEB. Instituto Internacional de Educação do Brasil, 2019.

EID. EmergingandReemergingInfectiousDiseases, RegionoftheAmericas.Human Rabies TransmittedbyBats in Pará State, Brazil. EID. WeeklyUpdates.Vol. 2, No. 14. 8 April, 2004.

GIL, Antônio Carlos. Como elaborar projetos de pesquisa, 4. ed. - São Paulo: Atlas, 2002.

LUZIO DOS SANTOS, Luís Miguel. Socioeconomia: solidariedade, economia social e as organizações em debate - São Paulo: Atlas, 2014.

MANCE, Euclides André. A Revolução das Redes: a colaboração solidária como alternativa pós-capitalista à globalização atual. Petrópolis: Vozes, 2000.

MANCE, Euclides André. Redes de colaboração solidária: aspectos econômicosfilosóficos: complexidade e libertação. Petrópolis: Vozes, 2002.

MIRANDA, Katiuscia; POTIGUAR, Manoel. Embarca Marajó: Estratégias locais de inovação, fortalecimento institucional e desenvolvimento sustentável. Belém: Instituto Internacional de Educação do Brasil, 2017.

SINGER, Paul. Introdução à Economia Solidária - $1^{\underline{a}}$ Ed. - São Paulo: Editora Fundação Perseu Abramo, 2002.

\section{Notas}

Alexandre Nunes da Silva

Mestrando em Gestão de Recursos Naturais e Desenvolvimento Local na Amazônia pela Universidade Federal do Pará.

Docente do Instituto Federal do Instituto Federal de Educação, Ciência e Tecnologia do Pará. Breves, Brasil.

alexandre.nunes@ifpa.edu.br

Gilberto Miranda Rocha

Doutor em Geografia pela Universidade de São Paulo.

Professor da Universidade Federal do Pará, Núcleo de Meio Ambiente. Belém, Brasil.

gilrocha@ufpa.br

Maria do Socorro Almeida Flores

Doutora em Direito pela Universidade Federal do Pará

Professora da Universidade Federal do Pará, Núcleo de Meio Ambiente. Belém, Brasil.

saflores@ufpa.br 
Endereço de correspondência do principal autor

Trav. Castilhos França, no 313, 68.000-000, Breves, PA, Brasil

\section{AGRADECIMENTOS}

Meus sinceros agradecimentos aos meus orientadores do Programa de Pós-graduação em Gestão de Recursos Naturais e Desenvolvimento Local na Amazônia (PPGEDAM) - Prof. Dr. Gilberto de Miranda Rocha e Prof. ‥ Dr.. Maria do Socorro Almeida Flores, e ao sempre prestativo amigo Prof. Dr. Mário Médice Costa Barbosa e a todos os agroextrativistas do Rio Acutipereira, em especial aos sempre empenhados cabocos marajoaras - Teofro Gomes Lacerda, Odivan Ferreira Corrêa, Sônia do Socorro de Oliveira Almeida, Nilson Corrêa da Silva, Maria Cláudia dos Santos Baia e Benedita do Socorro da Silva, pelo gentil e prestativo acolhimento na comunidade Santo Ezequiel Moreno.

\section{CONTRIBUIÇÃO DE AUTORIA}

Concepção e elaboração do manuscrito: SILVA, A. N.; ROCHA, G. M.; FLORES, M. S. A.

Coleta de dados: SILVA, A. N.

Análise de dados: SILVA, A. N.; BARBOSA, M. M. C.

Discussão dos resultados: SILVA, A. N.; BARBOSA, M. M. C.

Revisão e aprovação: SILVA, A. N.; ROCHA, G. M.; FLORES, M. S. A.

Caso necessário veja outros papéis em: https://casrai.org/credit/

\section{CONJUNTO DE DADOS DE PESQUISA}

Todo o conjunto de dados que dá suporte aos resultados deste estudo foi publicado no artigo e na seção "Materiais suplementares".

\section{FINANCIAMENTO}

NÃO SE APLICA.

\section{CONSENTIMENTO DE USO DE IMAGEM \\ NÃO SE APLICA.}

\section{APROVAÇÃO DE COMITÊ DE ÉTICA EM PESQUISA \\ NÃO SE APLICA.}

\section{CONFLITO DE INTERESSES}

NÃO SE APLICA.

LICENÇA DE USO - uso exclusivo da revista

Os autores cedem à Revista Internacional Interdisciplinar INTERthesis os direitos exclusivos de primeira publicação, com o trabalho simultaneamente licenciado sob a Licença Creative Commons Attribution (CC BY) 4.0 International. Estra licença permite que terceiros remixem, adaptem e criem a partir do trabalho publicado, atribuindo o devido crédito de autoria e publicação inicial neste periódico. Os autores têm autorização para assumir contratos adicionais separadamente, para distribuição não exclusiva da versão do trabalho publicada neste periódico (ex.: publicar em repositório institucional, em site pessoal, publicar uma tradução, ou como capítulo de livro), com reconhecimento de autoria e publicação inicial neste periódico.

\section{PUBLISHER}

Universidade Federal de Santa Catarina. Programa de Pós-graduação Interdisciplinar em Ciências Humanas. Publicação no Portal de Periódicos UFSC. As ideias expressadas neste artigo são de responsabilidade de seus autores, não representando, necessariamente, a opinião dos editores ou da universidade.

\section{EDITORES}

Javier Ignacio Vernal, Silmara Cimbalista e Selvino José Assmann (In Memoriam).

EDITOR ASSISTENTE - Eixo temático: “Amazônia: povos, conflitos e preservação” Luiz Barp

HISTÓRICO - uso exclusivo da revista Recebido em: 19-12-2019 - Aprovado em: 21-01-2020 - Publicado em: 26-02-2020 